\title{
EFFECT OF GATING SySTEM IMPROVEMENTS ON PRODUCTION Quality In High Pressure Die Casting
}

\author{
Anil Akdogan, Ali Serdar Vanli \& M. Numan Durakbasa
}
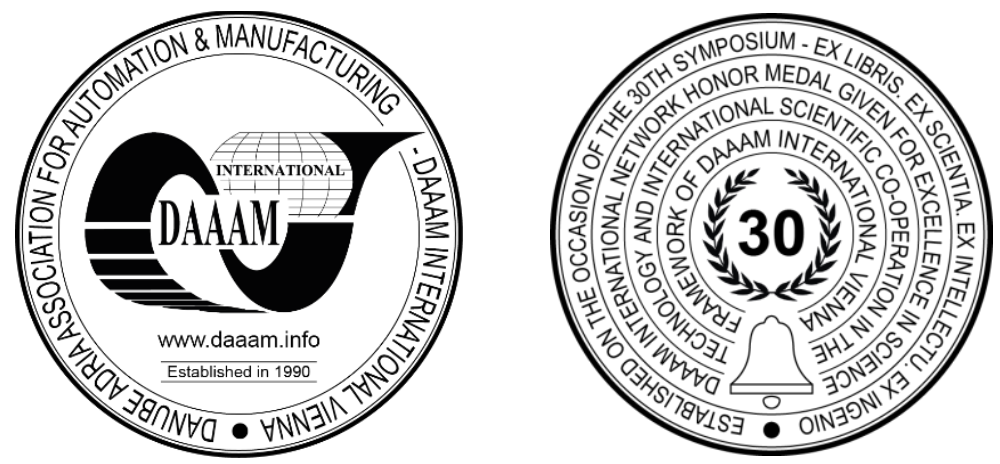

This Publication has to be referred as: Akdogan, A[nil]; Vanli, A[li] S[erdar] \& Durakbasa, N[uman] (2020). Effect of Gating System Improvements on Product Quality in High Pressure Die Casting, Proceedings of the 31st DAAAM International Symposium, pp.0459-0462, B. Katalinic (Ed.), Published by DAAAM International, ISBN 978-3-90273429-7, ISSN 1726-9679, Vienna, Austria

DOI: $10.2507 / 31$ st.daaam.proceedings.064

\begin{abstract}
The main goal in high pressure die casting process is to obtain better quality products with low porosity and high density. It is of course has a great importance to fill the mold cavity completely. Factors affecting product quality in the high pressure die casting process are diverse. Novel designed and improved gating systems have enabled to obtain casting parts with better quality and higher strength in this study. Furthermore, computer-aided simulation works, almost guarantees amortization for high-cost investments of high pressure die casting technology.
\end{abstract}

Keywords: Die-casting; Gating system; Design; Simulation; Quality.

\section{Introduction}

Die-casting is very complex process since flow momentum is a critical problem in the mold cavity filling operation especially in light metals under high pressure conditions. Shrinkage and gas porosity in the cast parts are the most common and the most important casting defects that occur during casting. Poor molten feeding systems, high molten metal velocities, long pouring time and incorrect vent placements can cause these kinds of defects easily [1]. Afterwards, they reduce the density of the compound material and cause the reduction of mechanical properties of the cast part. Besides the other elements of an integrated High Pressure Die Casting (HDPC) cell, high pressure die casting molds are consist one of the main technological developments for mass production processes in casting industry [2]. Certainly, a well-designed gating system is the first requirement in order to reach the desirable quality products in HDPC. Dimensions of the gating system need to be well calculated according to the product geometry. Each production part has different dimensions and geometrical specifications that may have an incorrect design which can cause production defects [3].

Computer aided simulation is a unique way to determine optimum process parameters and to predict possible risks and casting defects. Of course computer aided simulations can guide the designer closer to the optimal casting conditions and also elevate the casting quality. So that, with less experiment it gets easier to reach the better process conditions as well. There are many companies which use such simulations specialized even in high pressure die casting process in detail and many papers worked on the subject matter like being in [4] and [5]. 
In this study, an improved gating system letting the molten material AlSi9Cu3 to the mold cavity in HPDC process enabling with better quality part so that higher strength is designed and simulated in software clearly. By this design and simulation results, the parts can be produce as higher density and lower porosity with higher mechanical properties. As next, deformation analysis can be run and more accurate casting parameters can be examined.

\section{System Requirements}

\subsection{The part quality requirements}

A gating system sometimes can have a complex geometry with its pouring basin, sprue bush, gate, lateral and vertical canals like the sprue and the runner. Gating system firstly should provide a laminar flow in channels and minimize the turbulence, as well. At the second, it should be designed by considering the flow rate which is very important in filling phase. As the third, the molten metal velocity should be kept between the determined max. and min. critical limits. Of course, the gating system should convey the molten metal to the mold cavity and solidify after the part. Finally, the system should prevent the entry of slag, dross, inclusions into the mold cavity [6]. In order to avoid casting defects such as gas porosity, air entrapment, turbulent, early solidification, inclusion scraps, incomplete fillings and deformations, the vital precautions must be taken in the design stage. Some typical die casting defects are represented in Figure 1.

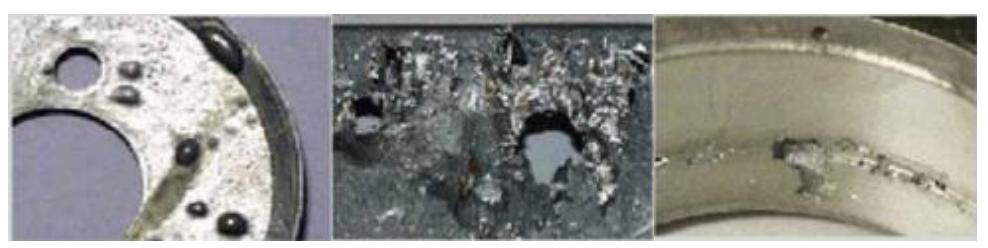

Fig. 1. Typical defects - Gas porosity (at left) - Incomplete filling (in the middle) - Shrinkage (at right)

\subsection{The gating system design requirements}

The gating system design starts with the determination of an appropriate gating entrance. Especially in inhomogeneous parts, geometry with different wall thickness designs, the runner entry should be given from the possible thickest area. In some cases, the sprue entrance is determinated according to the past experiences where the critical region is not being the thickest walled part. The runner entrance can be selected by the verifications via simulation applications. After the determination of the runner entrance and its design shape, the part placement in the mold needs to be determined and calculated [7]. In order to achieve the same quality criteria, the molten metal must enter all cavities at the same time and homogeneous filling needs to be supplied in multi-cavity molds [8]. Since there are several defect types, estimation of process risks and required precautions must be done quickly and precisely before the production with the help of computer simulation. Of course design works are unlimited issues and the aim of those kinds of works is to convey the molten material into the mold cavity throughout the finest detail without any problems. The limitations in this work are the die height and the space between the tie bars which are related with the locking force of the chosen die casting machine in the calculations.

\section{Gating System Design}

\subsection{The material}

In this study, an improved gating system design conveying the molten material AlSi9Cu3 to the mold cavity in HPDC process without problem. It is designed and simulated in software clearly. The chemical composition of the molten material AlSi9Cu3 is given in Table 1.

\begin{tabular}{|l|l|l|l|l|l|l|l|l|l|}
\hline $\mathrm{Fe}(\boldsymbol{\%})$ & $\mathrm{Si}(\boldsymbol{\%})$ & $\mathrm{Cu}(\boldsymbol{\%})$ & $\mathrm{Mn}(\boldsymbol{\%})$ & $\mathrm{Mg}(\boldsymbol{\%})$ & $\mathrm{Zn} \mathrm{( \% )}$ & $\mathrm{Ni}(\boldsymbol{\%})$ & $\mathrm{Ti}(\boldsymbol{\%})$ & $\mathrm{Pb}(\boldsymbol{\%})$ & $\mathrm{Sn}(\boldsymbol{\%})$ \\
\hline 1.00 & 8.00 & 3.5 & 0.50 & 0.30 & 1.00 & 0.20 & 0.20 & 0.10 & 0.10 \\
\hline
\end{tabular}

Table 1. Chemical composition of the AlSi9Cu3

\subsection{Design examinations}

The study was started with the first design as given in Figure 2 (left) for an industrial product. The mold is considered as six-cavity. It is run in the simulation and observed that it was not suitable in homogenous filling. While the cavities closer to the sprue-well is almost complete, the molten metal has just arrived in the upper cavities. Considering the problems observed in the first design, the second gating system was designed. 
In order to prevent the molten metal from reaching the closer cavities early, the axes of the closer cavities were calculated and re-designed. Additionally, the runner was oriented in reverse. The second gating design shown in Figure 2 (right) was simulated. It was observed that the early filling problem was still there.

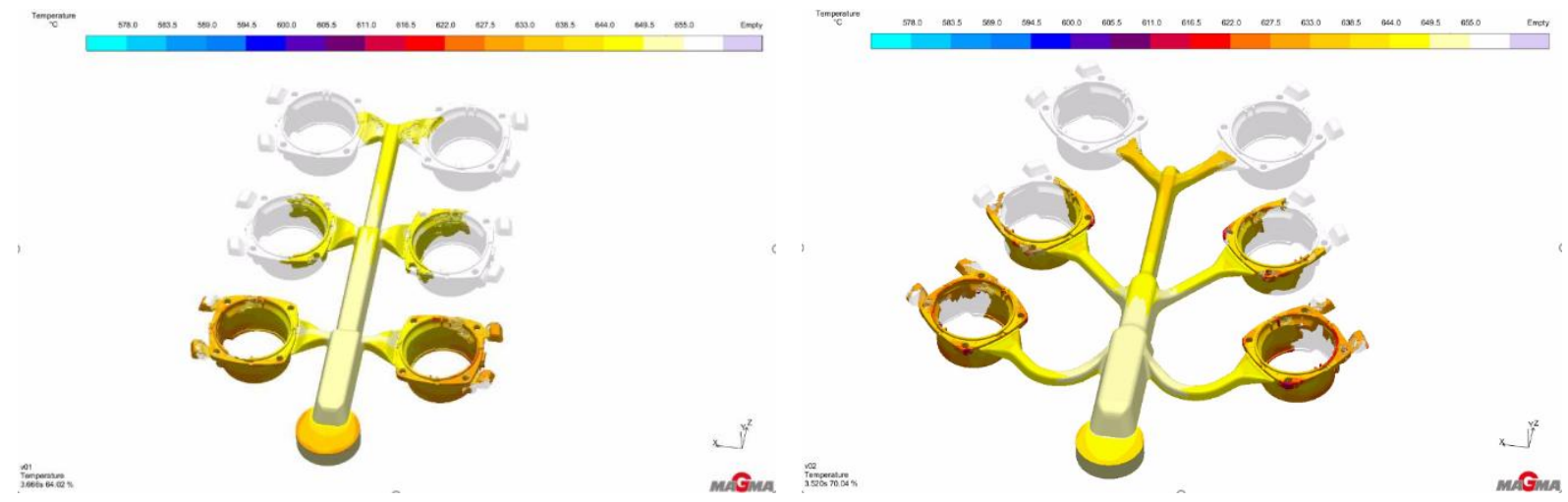

Fig. 2. The first (at left) and the second (at right) gating system design simulations via temperature grade

\subsection{The modified design of gating system}

Considering the negative results in the first and the second designs, the concept was changed and the third design was done and simulated. When the simulation results were examined, it was seen that the liquid metal reached all cavities almost at the same time (Figure 3). The new design stage was started with determining the appropriate gating entrance considering the critical region, the thickest walled part. The gating locations are selected by verifications via simulation applications. The runners were completely developed. After the design of the gating entrance and its geometry, the part placement in the mold is determined and calculated.

In this work, a completely new gating system design is made for the product. The described results by this research will lead further design works as a basic platform to improve filling ability of the molten material in to the gating channels and cavity. It can help to run not only solidification grade observations but also the other required deformation analysis.

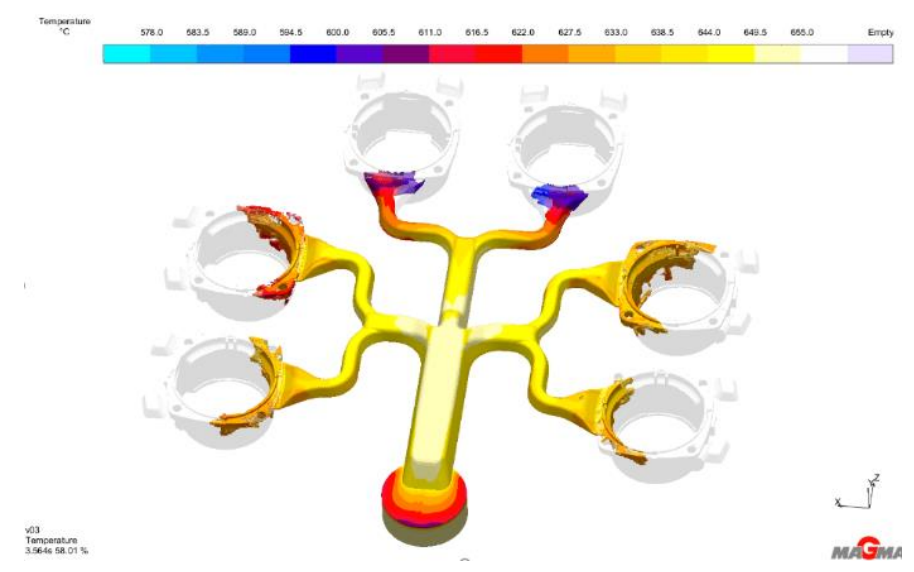

Fig. 3. The modified gating system design simulation via temperature grade

\section{Conclusions}

Gating system design and various process parameters are effective factors on product quality and mechanical properties in HPDC process. In this work, a better gating system design is calculated for AlSi9Cu3 aluminum alloy for die casting process and it is studied and analyzed through computer aided simulations. At first, the gating system and runners was initially developed. Then, a consequent and gradual optimization of the feeding system of the molten material was carried out. Below achievements can be listed;

- The molten material can always be distributed at uniform velocities during the filling. It is an reducing effect on the possibility of casting waste and the wear of the mold;

- The mold cavity is completely solidified before the sprue. It guarantees better disposing of gases and an efficient outcome for the third phase;

- $\quad$ The shrinkage caused defects and air entrapping has been eliminated. 
The parameters calculated during the design are verified and stored in virtual environment by means of the simulation program. In the future plans, the more precise values of the process parameters are going to be determined by considering the effects. These parameters are going to be shared with the production department. The shared parameters will be tried at the first casting. If necessary, changes are made and non-destructive testing used to determine the possible defects. The effects of new parameters on the quality of the parts will be observed.

Even if, all risk possibilities is considered during the design stage of the gating system with the optimum selection of the process parameters, designers and the manufacturers should consider the whole integrated components of a HPDC system affecting to the cast part quality.

\section{References}

[1] Analysis of Casting Defect Committee. (1947). AFS, Published by Chicago, American Foundrymen's Association, NY, USA.

[2] Kwon, Hyuk-J. \& Kwon, Hong-K. (2019). Computer aided engineering (CAE) simulation for the design optimization of gate system on high pressure die casting (HPDC) process, Robotics and Computer-Integrated Manufacturing, ISSN: 0736-5845, Vol: 55, Page: 147-153

[3] Erbul, A.; Vanli, A. S.; Akdogan, A. \& Durakbasa, M. N. (2017). Gating System Design and Optımızatıon in Sand Mold Casting of Cast Irons, Chapter 14 in DAAAM International Scientific Book 2017, pp.173-190, B. Katalinic (Ed.), Published by DAAAM International, ISBN 978-3-902734-12-9, ISSN 1726-9687, Vienna, Austria DOI:10.2507/daaam.scibook.2017.14

[4] Mohamad El M., Mancia, T., Buonadonna, P., Guzzini, L., Snatini, E. \& Forcellese, A. (2020). Design optimization of gate system on high pressure die casting of AlSi13Fe alloy by means of finite element simulations. Procedia CIRP Volume 88, 2020, Pages 509-514

[5] Kyu Seo K. \& Kyu Kwon, H. (2013). Simulation Study and Application on HPDC Process with Automobile Part, Advanced Materials Research, 658, pp. 281-286

[6] ASM International (1998). ASM Handbook Volume 15 Casting, ISBN: 978-0-87170-711-6, Ohio, USA

[7] Vanli, A.S. \& Akdogan, A. (2019). Manufacturing Automation for Magnesium Die Casting. In: Majstorovic V., Durakbasa N. (Ed.), Proceedings of the 12th International Conference on Measurement and Quality Control Cyber Physical Issue. IMEKOTC14. Lecture Notes in Mechanical Engineering. Springer, Cham. https://doi.org/10.1007/978-3-030-18177-2_13

[8] Çelik, A., Gençalp, E. \& Vanlı, A. S., (2018) Optimum Design and Verification in HPDC by Simulation, TÜDÖKSAD 10. International Casting Congress, İstanbul, Turkey. 